\title{
Relationships among Stress, Positive Affectivity, and Work Engagement among Registered Nurses
}

\author{
Jazreel Hui Min Thian', Premarani Kannusamy ${ }^{2}$, Hong-Gu He1, Piyanee Klainin-Yobas ${ }^{{ }^{*}}$ \\ ${ }^{1}$ Alice Lee Centre for Nursing Studies, National University of Singapore, Singapore City, Singapore \\ ${ }^{2}$ Assisi Hospice, Singapore City, Singapore \\ Email: nurpk@nus.edu.sg
}

Received 23 January 2015; accepted 7 February 2015; published 11 February 2015

Copyright (c) 2015 by authors and Scientific Research Publishing Inc.

This work is licensed under the Creative Commons Attribution International License (CC BY). http://creativecommons.org/licenses/by/4.0/

(c) (i) Open Access

\begin{abstract}
Work stress is intrinsic to nursing. It negatively affects nurses' health and well-being. Nurses, who are under stress, often report job dissatisfaction, intention to quit their job, burn out, and physical complaints. This study aimed to identify sources of work stressors among registered nurses and examine the interrelationships among stress, positive affectivity, and work engagement. A descriptive-correlational research design was conducted. A sample of 195 full-time nurses was recruited from a tertiary hospital in Singapore. Data were collected via self-reported questionnaires and then analyzed using descriptive statistics and path analyses. Work stressors experienced by most nurses were workload, time pressure, inadequate reward, inadequate patient interaction, and unmanageable emotional demands of job. Positive affectivity had a significant negative relationship with stress in the past month but had a significant positive relationship with three components of work engagement. Worksite interventions may be developed to help nurses manage stress. Particularly, workshops enhancing positive affectivity and work engagement could be offered in health care facilities.
\end{abstract}

\section{Keywords}

Positive Affectivity, Registered Nurses, Work Stress, Work Engagement

\section{Introduction}

Work stress among nurses has become a global phenomenon occurring in many countries, including Singapore. It often makes nurses feel dissatisfied with their jobs (Seo et al., 2004), leading to high absenteeism, intention to

"Corresponding author.

How to cite this paper: Thian, J. H. M., Kannusamy, P., He, H.-G., \& Klainin-Yobas, P. (2015). Relationships among Stress, Positive Affectivity, and Work Engagement among Registered Nurses. Psychology, 6, 159-167. 
leave the institution, increased turnover rate, and shortage of nurses (Lim et al., 2010a; Lim et al., 2010b; Wu et al., 2010). Work stress refers to the temporary adaptation process in an occupation associating with physiological or physical and cognitive symptoms. Stress at work is associated with burnout (Hanrahan et al., 2010) and health problems including cardiovascular diseases, irritable bowel syndrome, hypertension and cancer (Murray et al., 2004; Lim et al., 2010b). Work stress is related to reduced work performance, decreased quality care, increased infection in hospitals and lower patient satisfaction (Cimiotti et al., 2012; Nantsupawat et al., 2011). To ensure nurses' work performance and quality care, there is a need to identify variables contributing to lowered stress and increased well-being among nurses.

Singapore uses a comprehensive health care system, where the government assures affordable healthcare via compulsory savings from the citizens. In this system, the citizens are expected to co-pay their medical expenses (depending on their incomes) and to receive a government subsidy (Lim et al., 2010b). It is estimated that there are 57 nurses per 10,000 Singaporeans (Lim et al., 2010b). This is considered a small number in comparison to other countries like Australia, where the nurse-patient ratio is 110:10,000 (Australian Bureau of Statistics, 2008). The shortage of nurses in Singapore may contribute to high work stress and work overload among nurses (Lim et al., 2010b).

Work stress is associated with various factors, including undesirable organization culture (such as unclear organizational structure and poor leadership), dissatisfied career development (such as job insecurity, unfair evaluation system, and the lack of promotion prospects), unpleasant work content (such as monotonous tasks and unpredictable working hours), insufficient social support at work and home-work interface (such as conflicting demands between home and work) (Leka et al., 2003). Job demands (physical or psychological efforts requiring to execute the job) are linked to work overload (Freeney \& Tiernan, 2009), fatigue, psychosomatic symptoms and emotional exhaustion (Adriaenssens et al., 2011). Interpersonal problems (conflict with colleagues, supervisors and medical staff) increase work stress among nurses and may lead to compromised patient safety via medical errors and adverse patient outcomes (Baldwin \& Daugherty, 2008). Furthermore, nurses with high levels of role overload, role conflict, and role ambiguity reported higher work stress and lower job satisfaction (Chen et al., 2007).

Personal characteristics play a crucial role in one's ability to withstand stress and they affect how one perceives their environment (Alarcon et al., 2009). Positive affectivity (PA) is one of the personality characteristics deserving further investigations. PA refers to an ability to experience positive emotions in different situations (Watson et al., 1988). Individuals with high PA tend to be earnest, passionate and energetic whereas low-PA individuals are passive, indifferent and lethargic (Van Yperen, 2003). High PA is associated with increased job satisfaction, better job attitudes and performance, lower levels of burnout, and decreased turnover intention (Thian et al., 2013).

Work engagement (WE) refers to a persistent, positive, affective-cognitive state of fulfilment among employees with three distinct dimensions: vigour, dedication, and absorption (Schaufeli et al., 2002). In Schaufeli and Bakker (2004), vigour is described as having high levels of work commitment and boundless energy, even when encountering challenges. Dedication refers to individuals' sense of importance, ardent expression, inspiration, and pride at work. Absorption is defined as an absolute focus that one finds difficulty dissociating from work (Freeney \& Tiernan, 2009). The concepts of PA and WE are postulated to be inversely correlated with work stress and other negative job outcomes_(Schaufeli \& Bakker, 2004; Simpson, 2009a).

According to the Affective Shift Theoretical Model of Work Engagement (ASWE: Bledow et al., 2011), PA is postulated to be positively linked with work engagement. High-PA individuals are often happy, socialable, and lively as they have a high baseline of positive mood (Watson \& Clark, 1984). Hence, they tend to be wellengaged while performing tasks and activities at work (Bledow et al., 2011). However, this theoretical link was not well-supported by current empirical evidence. Furthermore, little is known about the relationships among stress, PA and work engagement, suggesting knowledge gaps in the literature (Thian et al., 2013).

To minimise such knowledge gaps, this study aimed to explore the interrelationship among stress, PA, and work engagement in registered nurses working in a tertiary hospital in Singapore and to identify common work stressors experienced by nurses. Knowledge generated from this study would contribute to the literature, adding more understanding to the phenomena of interest. Furthermore, positive findings from this study may pave a way to develop interventions which help nurses enhance their positive affectivity, manage work stress more effectively and thus maximize their well-being. 


\section{Methods}

\subsection{Research Design}

This study used a cross-sectional, descriptive correlational research design. This research design was deemed appropriate as it allowed exploring interrelationship among study variables in a naturally-occurring setting in a certain period (Polit \& Beck, 2006). Data were collected from January to March 2012.

\subsection{Participants and Settings}

All 300 Registered Nurses who worked at 14 general wards in a tertiary hospital in Singapore were target population for this study. Participants were eligible if they: 1) were full-time Registered Nurses (RNs) working in general wards; 2) had at least two months of working experience in this hospital as two months were considered an orientation period for new RNs, 3) were between 21 to 62 years old regardless of their gender, and 4) were able to communicate in English. Note that 62 is a retirement age in Singapore. Potential participants were excluded if they: 1) worked as temporary staff and 2) had severe medical illnesses and/or mental disorders that required on-going treatments or hospitalization. Nurses who satisfied the inclusion and exclusion criteria were approached to ascertain the representative of the study population.

\subsection{Sample Size Determination}

Power analysis was used to calculate an adequate sample size and the following parameters were used: effect size, level of significance, and power (Cohen, 1988). An effect size ( $\mathrm{f}^{2}$ of 0.51 ) was calculated using findings from a non-experimental study that investigated interrelationships among job satisfaction, intention to leave, job search behaviour and work engagement (Simpson, 2009b). Using the effect size of 0.51, the level of significance of 0.05 , and recommended power of $80 \%$, a sample size of 26 would be minimally adequate for this study (Cohen, 1988). To maximize generalizability of findings, we attempted to recruit participants as many as possible.

\subsection{Instruments}

Data were collected via self-administered questionnaires containing the following measurements:

Positive Affectivity (PA) was measured with the 10-item Positive Affect Subscale of the Positive Affect and Negative Affect Scale (PANAS; Watson et al., 1988; Bakker et al., 2008). Respondents rated on a 5-point Adjectival scale ranging from " 1 ” (very slightly or not at all) to " 5 ” (extremely). Possible range of scores was 10 50, with high scores indicating high level of PA. For this study, Cronbach's alpha of this scale was 0.94, suggesting excellent reliability.

Work engagement was measured with the 17-item Utretch Work Engagement Scale (UWES) capturing three dimensions: vigour, absorption and dedication (Schaufeli \& Bakker, 2004). Participants responded on a 7-point scale ranging from "0" (never) to "6" (every day or always). Possible range of scores was 0 - 102, with high scores indicating high levels of work engagement. Findings from factor analysis showed that this scale has three distinct factors (Seppälä et al., 2009), supporting the construct validity. For the current sample, Cronbach's alpha of the total scale was $0.94 ; 0.84$ for the vigour, 0.89 for dedication, and 0.81 for absorption subscales.

Stress was measured with the 10-item Perceived Stress Scale (PSS; Cohen et al., 1983) and the single-item Stress Scale (SSS) developed by the researchers. The PSS measured stress experienced by nurses during the past month. Respondents rated on a 5-point scale ranging from " 0 " (never) to " 4 " (very often). Possible scores were in the range of 0 - 40, with higher scores indicating greater stress. Cronbach's alpha of the PSS on the current sample was 0.72 . The PSS is one of the most widely used instruments and its validity was well-documented in previous research. Particularly, it has demonstrated significant relationships with measures of self-reported health, health services, health behavior measures, smoking status, help-seeking behavior (Cohen \& Williamson, 1988).

The SSS is a visual analogue scale devised to capture subjective stress experienced by study participants in the past week. This scale was represented with a horizontal continuous line anchored with "no stress" (0) at one end and "very stressed" (10) at the other. Possible scores ranged from one to 10 with higher scores indicating higher stress. In this study, the SSS had a significant correlation with the PSS ( $r=0.60, p<0.001)$. This evidence supported the concurrent validity of the SSS. 
Work stressors were measured by the Work stressor Checklist for Nurse (JSC-N) (Thian, 2012). The researchers created this scale based on the Maslach and Leiter (1997)'s burnout and engagement model and previous empirical evidence. The JSC-N comprises a list of 15 work stressors and one open-ended question. Participants were asked to select "yes" (1) or "no" (0) in relation to the list work stressors. For the content validation of the JSC-N, two mental health nurses and one nurse educator were asked to review the scale. Afterward, we asked 10 registered nurses to review the scale to ensure that its contents (such as questions and instructions) are clear, simple, and easy to understand

\subsection{Data Collection Procedure}

Prior to commencing the study, we obtained approval from hospital ethics committee in Singapore. We scheduled meetings with nurse managers of 14 general wards to explain the study and seek their support in identifying potential participants. Subsequently, questionnaire packages were distributed to nurses who met the eligible criteria. The package contained a participant information sheet, questionnaire, and envelope. Participants were assured that their contribution was voluntary. Completed questionnaires were to be sealed in the supplied envelope and placed in the designated box situated at nursing managers' office of each respective ward. To assure anonymity, participants were urged not to place any form of identifier on the questionnaire. Given that this study used anonymous questionnaires, the participants were not required to sign a consent form. This waiver of written consent form was granted by hospital ethics committee.

\subsection{Data Analyzes}

Data were analyzed using IBM SPSS Statistics version 19.0 (IBM Cooperation, 2012). Univariate data analyses (such as frequency, percentage, mean, quartiles and standard deviation) were performed to describe participants' characteristics and study variables. Reliability analyses were conducted to describe internal consistency of the measurements. Path analyses were used to test the relationships among stress, positive affectivity, and three components of work engagement (vigour, dedication, and absorption). Standardized regression coefficients ( $\beta$ ) would represent the effect of an independent variable on a dependent variable. Furthermore, $\mathrm{R}^{2}$ would indicate the amount of variance explained by dependent variables.

\section{Results}

Although 300 questionnaires were distributed to nurses working in general wards, only 195 completed questionnaires were returned, making up a response rate of $65 \%$. Results from univariate analyses revealed that participants were predominantly female $(91.3 \%, \mathrm{n}=178)$, single $(65.1 \%, \mathrm{n}=127)$; and with no children $(72.8 \%, \mathrm{n}=$ 142). The largest group were the Singaporean $(39.5 \%, n=77)$, followed by Filipino $(19.0 \%, n=37)$ and Malaysian nurses $(10.3 \%, n=20)$. Chinese nurses accounted for $37.4 \%(n=73)$ of the sample, followed by the Malay $(15.9 \%, \mathrm{n}=15.9)$ and Indian $(13.3 \%, \mathrm{n}=26)$. Regarding education, nurses received Bachelor's degree (48.2\%, $\mathrm{n}=94)$ and Diploma $(46.2 \%, \mathrm{n}=90)$. Descriptive statistics of study variables were illustrated in Table 1.

\subsection{Work Stressors}

The greatest work stressors experienced by respondents was high workload $(83.1 \%, \mathrm{n}=162)$, followed by time

\begin{tabular}{|c|c|c|c|c|c|c|c|}
\hline Study variables & $\mathrm{n}$ & Possible range & Mean & Standard deviation & Skewness & Kurtosis & Cronbach's alpha \\
\hline Work engagement & 195 & $0-102$ & 62.19 & 17.32 & -0.25 & 0.48 & 0.94 \\
\hline Vigour & 195 & $0-36$ & 20.20 & 6.57 & -0.05 & 0.02 & 0.84 \\
\hline Dedication & 195 & $0-30$ & 20.41 & 5.87 & -0.40 & -0.04 & 0.89 \\
\hline Absorption & 195 & $0-36$ & 21.76 & 6.44 & -0.18 & 0.47 & 0.81 \\
\hline Positive affectivity & 195 & $10-50$ & 34.24 & 7.53 & -0.12 & 0.20 & 0.94 \\
\hline Stress (past week) & 195 & $0-40$ & 19.29 & 4.14 & 0.38 & 0.87 & 0.72 \\
\hline Stress (past month) & 171 & $0-10$ & 5.20 & 2.15 & -0.05 & -0.45 & - \\
\hline
\end{tabular}


pressure $(57.9 \%, n=113)$, inadequate reward $(32.8 \%, n=64)$, inadequate patient interaction $(24.1 \%, n=47)$, unmanageable emotional demands of job $(22.6 \%, \mathrm{n}=44)$ and poor professional status of nurses $(22.6 \%, \mathrm{n}=44)$ (Table 2). The least problematic items for nurses were poor communication with co-workers $(8.2 \%, \mathrm{n}=16)$ and lack of professional feedback $(7.2 \%, \mathrm{n}=14)$.

\subsection{Relationships between Stress, Positive Affectivity, and Work Engagement}

Results from path analyzes are portrayed in Figure 1. It is indicated that $40 \%$ of variance $\left(\mathrm{R}^{2}=0.40\right)$ on the Table 2. Work stressors among registered nurses.

\begin{tabular}{lcc}
\hline \multicolumn{1}{c}{ Work stressors } & Yes n (\%) & No n (\%) \\
\hline 1) High workload or high patient to nurse ratio. & $162(83.1)$ & $33(16.9)$ \\
2) Time pressure. & $113(57.9)$ & $82(42.1)$ \\
3) Inadequate reward system. & $64(32.8)$ & $131(67.2)$ \\
4) Inadequate patient interaction. & $47(24.1)$ & $148(75.9)$ \\
5) Unmanageable emotional demand of job. & $44(22.6)$ & $151(77.4)$ \\
6) Poor professional status of nurses. & $44(22.6)$ & $151(77.4)$ \\
7) Limited support from colleagues. & $40(20.5)$ & $155(79.5)$ \\
8) Poor communication with multi-disciplinary team e.g. doctors, physiotherapist. & $39(20.0)$ & $156(80.0)$ \\
9) Limited social support from supervisors. & $35(17.9)$ & $160(82.1)$ \\
10) Poor structure of communication in hospital. & $30(15.4)$ & $165(84.6)$ \\
11) Poor communication with patients. & $24(12.3)$ & $171(87.7)$ \\
12) Limited job control. & $23(11.8)$ & $172(88.2)$ \\
13) Lack of information to perform well during job. & $21(10.8)$ & $174(89.2)$ \\
14) Poor communication with co-workers. & $16(8.2)$ & $179(91.8)$ \\
15) Lack of professional feedback. & $14(7.2)$ & $181(92.8)$ \\
16) Others. & $12(6.2)$ & $183(93.8)$ \\
\hline
\end{tabular}



Figure 1. Relationships among stress, positive affectivity, and work engagement (vigour, dedication, absorption). 
vigour subscale were explained by all independent variables in the model (PA, stress in the past week, and stress in the past month). Furthermore, these number were $49 \%\left(\mathrm{R}^{2}=0.49\right)$ for dedication and for absorption subscales $\left(\mathrm{R}^{2}=0.35\right)$.

PA had significant positive effects on vigour $(\beta=0.58, p<0.01)$, dedication $(\beta=0.66, p<0.01)$, and absorption $(\beta=0.57, p<0.01)$. PA also had significant negative effects on stress in the past week $(\beta=-0.25, p<0.01)$ and stress in the past month $(\beta=-0.36, p<0.01)$.

However, there were no significant relationships between stress in the past week and: vigour $(\beta=-0.05, p=$ $0.40)$, dedication $(\beta=-0.07, p=0.21)$, and absorption $(\beta=-0.06, p=0.31)$. Similarly, stress in the past month did not have significant relationships with three dimensions of working engagement: vigour $(\beta=-0.10, p=$ $0.10)$, dedication $(\beta=-0.06, p=0.26)$, and absorption $(\beta=-0.01, p=0.92)$.

\section{Discussion}

This study aimed to describe work stressors experienced by registered nurses working at 14 general wards in a tertiary hospital in Singapore and to explore the relationships among stress, positive affectivity, and work engagement. Findings suggested that the most frequently-reported stressor for nurses was work overload. Similarly, previous studies cited that workload was the most common stressor experienced by nurses in many countries (Freeney \& Tiernan, 2009). This may be because nurses working in general wards in Singapore provide direct care to patients with diverse health conditions, prepare patients for various investigation and treatment procedures, deal with patients' and families' emotional problems, complete abundant paperwork, among others. Moreover, the current shortage of nurses in Singapore probably aggravates the workload problem, contributing to increased stress among nurses.

Other work stressors reported by nurses in this study were time pressure, inadequate patient interaction, among others. Another exploratory study conducted in Singapore revealed that nurses experienced poor social relations in the workplace, bureaucratic constraints, and poor job prospects (Chan et al., 2000). Nurses also reported low income and occupational prestige with minimal autonomy at work (Chan et al., 2000).

Results from this study highlighted that nurses with higher levels of PA were more likely to report greater working engagement: vigour, dedication, and absorption. To our knowledge, these relationships have not been tested on nurses and other health care providers. Nevertheless, there is one study conducted on software developers and computer scientists suggesting that employees with high positive affectivity in the morning are more likely to experience high levels of work engagement in the afternoon (Bledow et al., 2011). Furthermore, people with high positive affectivity were more likely to engage to their work despite negative experiences arising during the day (Bledow et al., 2011). Our findings provided support to the affective shift model of work engagement (Bledow et al., 2011), which postulates that work engagement is closely linked to the presence of positive affectivity. High-PA people are usually full of energetic, contented, joyful, optimistic, and goal-directed while working despite the presence of problematic situations. They can cope more effectively with negative events, tend to engage in task/activities that are most rewarding, and expect positive outcomes from the involved tasks (Bledow et al., 2011; Schaufeli \& Bakker, 2004; Watson et al., 1988). Positive affectivity contributes to the motivational fulfilment that individuals strive towards at work, and therefore, being highly engaged (Bledow et al., 2011).

Singaporean nurses with high levels of positive affectivity were more likely to report lower levels of stress in the past week and past month. Similarly, previous studies reported that high PA was associated with lower systematic blood pressure, an objective measure of stress (Steptoe et al., 2007). As postulated by Watson et al. (1988), people with high positive affectivity have the ability to experience positive emotions in different situations and they tend to be joyful, energetic, and enthusiastic. It is possible that high-PA nurses view situations at workplace through their positive lenses and tend to look at problematic situations as manageable challenges. Therefore, they do not perceive the situations as stress. Unfortunately, there is a scarcity of studies investigating the relationships between positive affectivity and perceived stress. Most research examined the relationship between positive affectivity and other variables including job attitudes and behaviour, job satisfaction, absenteeism and work performance (Alarcon et al., 2009). Hence, future research can be directed in examining the relationship between stress and positive affectivity in various populations to better understand this phenomenon.

\subsection{Limitations}

Few methodological limitations are noted in this study. First of all, the low response rate might limit the genera- 
lizability of findings to the target population. We might have missed important information from the non-responders. Secondly, data were collected from only one tertiary hospital in Singapore. Results from this study may not be generalizable to other healthcare facilities or community-based settings. Finally, the use of cross-sectional research design would not allow the establishment of causality among study variables (Polit \& Beck, 2006).

\subsection{Implications to Practice}

Findings from this study add knowledge to the limited literature; and have implications in clinical practice and management. To minimize work stressors, hospital administrators may work with the Singaporean government to retain the nursing workforce by increasing nurses' salaries and fringe benefits. Regarding time pressure, the hospital management may assign preceptors to the nurses with lesser experience. Besides guidance in terms of workflow, the preceptors can share how they prioritize their work and perform tasks more efficiently. Support groups can be formed so that nurses will have the opportunity to share their work experiences and/or brainstorm to produce solutions for their problems.

Interventions can be developed to enhance the positive affectivity and work engagement. Workshops aiming at enhancing positive affectivity, optimism, and coping skills may be offered to staff nurses. Necessary job resources such as professional feedback, support from managers and counselling can be provided. Bakker et al. (2008) suggested using self-regulation to manage work engagement. Individuals can be motivated to their goals through two means: promotion-focused or prevention focused methods. Promotion-focused individuals are motivated by growth, development, and preferred gain over losses while prevention-focused individuals are responsive to needs and preferred avoidance of loss (Bakker et al., 2008). Nurses can set their professional goals, share them with nursing managers, and strive to work towards the agreed goals. Rewards may be offered to those who accomplish their goals.

\subsection{Recommendations for Future Research}

Additional research is needed. Longitudinal studies can be conducted to explore the casual relationships among stress, positive affectivity, and work engagement in Singapore and other countries. Our study identified the common sources of work stressors but did not measure the intensity of work stress experienced. In addition, it did not measure other variables that may affect how nurses perceive stress (such as coping strategies, personality, and family-related variables). Future research should be directed at these areas to provide a comprehensive view of the phenomena. Our study may be replicated in nurses with other specialty (such as mental health, critical care, and pediatric nursing), healthcare facilities, ethnic groups, and countries. Additional research should be directed at developing interventions for enhancing stress management skills; and strengthening of positive affectivity and work engagement.

\section{Conclusion}

To our knowledge, this is the first study that examined the relationships among stress, positive affectivity, and work engagement among health care providers. Findings showed that nurses in Singapore experienced similar sources of work stress (such as workload) as nurses in other countries do. Positive affectivity was positively associated with work engagement (vigour, dedication, and absorption), and negatively related to perceived stress in the past month. Nurse administrators should initiate worksite interventions/strategies to reduce stress, and to enhance positive affectivity and work engagement in nurses. Future research can be directed towards testing the effectiveness of the worksite interventions.

\section{References}

Adriaenssens, J., De Gucht, V., Van Der Doef, M., \& Maes, S. (2011). Exploring the Burden of Emergency Care: Predictors of Stress-Health Outcomes in Emergency Nurses. Journal of Advanced Nursing, 67, 1317-1328. http://dx.doi.org/10.1111/j.1365-2648.2010.05599.x

Alarcon, G., Eschleman, K. J., \& Bowling, N. A. (2009). Relationship between Personality Variables and Burnout: A MetaAnalysis. Work \& Stress, 23, 244-263. http://dx.doi.org/10.1080/02678370903282600

Australian Bureau of Statistics (2008). Selected Health Occupations: Australia, 2006. http://www.abs.gov.au/ausstats/abs@.nsf/mf/4819.0 
Bakker, A. B., Schaufeli, W. B., Leiter, M. P., \& Taris, T. W. (2008). Work Engagement: An Emerging Concept in Occupational Health Psychology. Work \& Stress, 22, 187-200. http://dx.doi.org/10.1080/02678370802393649

Baldwin, D. R., \& Daugherty, S. (2008). Interprofessional Conflict and Medical Errors: Results of a National Multi-Specialty Survey of Hospital Residents in the US. Journal of Interprofessional Care, 22, 573-586. http://dx.doi.org/10.1080/13561820802364740

Bledow, R., Schmitt, A., Frese, M., \& Kuhnel, J. (2011). The Affective Shift Model of Work Engagement. Journal of Applied Psychology, 96, 1246-1257. http://dx.doi.org/10.1037/a0024532

Chan, K. B., Lai, G., Ko, Y. C., \& Boey, K. W. (2000). Work Stress among Six Professional Groups: The Singapore Experience. Social Science \& Medicine, 50, 1415-1432. http://dx.doi.org/10.1016/S0277-9536(99)00397-4

Chen, Y.-M., Chen, S.-H., Tsai, C.-Y., \& Lo, L. Y. (2007). Role Stress and Job Satisfaction for Nurse Specialists. Journal of Advanced Nursing, 59, 498-509. http://dx.doi.org/10.1111/j.1365-2648.2007.04339.x

Cimiotti, J. P., Aiken, L. H., Sloane, D. M., \& Wu, E. S. (2012). Nurse Staffing, Burnout, and Health Care-Associated Infection. American Journal of Infection Control, 40, 486-490. http://dx.doi.org/10.1016/j.ajic.2012.02.029

Cohen, J. (1988). Statistical Power Analysis for the Behavioral Sciences. Hillsdale, NJ: Lawrence Erlbaum Associates.

Cohen, S., \& Williamson, G. (1988). Perceived Stress in a Probability Sample of the United States. In S. Spacapan, \& S. Oskamp (Eds.), The Social Psychology of Health. Newbury Park, CA: Sage.

Cohen, S., Kamarck, T., \& Mermelstein, R. (1983). A Global Measure of Perceived Stress. Journal of Health and Social Behavior, 24, 385-396. http://dx.doi.org/10.2307/2136404

Freeney, Y., \& Tiernan, J. (2009). Exploration of the Facilitators of and Barriers to Work Engagement in Nursing. International Journal of Nursing Studies, 46, 1557-1565. http://dx.doi.org/10.1016/j.ijnurstu.2009.05.003

Hanrahan, N. P., Aiken, L. H., McClaine, L., \& Hanlon, A. L. (2010). Relationship between Psychiatric Nurse Work Environments and Nurse Burnout in Acute Care General Hospitals. Issues in Mental Health Nursing, 31, 198-207. http://dx.doi.org/10.3109/01612840903200068

IBM Cooperation (2012). SPSS Advanced Statistics. http://www-01.ibm.com/software/analytics/spss/products/statistics/advanced-statistics/

Leka, S. L., Griffiths, A., \& Cox, T. (2003). Work Organization and Stress: Systematic Problem Approaches for Employers, Manages and Trade Union Representatives. Geneva: World Health Organization.

Lim, J., Bogossian, F., \& Ahern, K. (2010a). Stress and Coping in Australian Nurses: A Systematic Review. International Nursing Review, 57, 22-31. http://dx.doi.org/10.1111/j.1466-7657.2009.00765.x

Lim, J., Bogossian, F., \& Ahern, K. (2010b). Stress and Coping in Singaporean Nurses: A Literature Review. Nursing \& Health Sciences, 12, 251-258. http://dx.doi.org/10.1111/j.1442-2018.2010.00514.x

Maslach, C., \& Leiter, M. P. (1997). The Truth about Burnout. San Francisco: CA: Jossey-Bass.

Murray, C. D. R., Flynn, J., Ratcliffe, L., Jacyna, M. R., Kamm, M. A., \& Emmanuel, A. V. (2004). Effects of Acute Physical and Psychological Stress on Gut Autonomic Innervations in Irritable Bowel Syndrome. Gastroenterology, 127, 16951703. http://dx.doi.org/10.1053/j.gastro.2004.08.057

Nantsupawat, A., Srisuphan, W., Kunaviktikul, W., Wichaikhum, O., Aungsuroch, Y., \& Aiken, L. H. (2011). Impact of Nurse Work Environment and Staffing on Hospital Nurse and Quality of Care in Thailand. Journal of Nursing Scholarship, 43, 426-432. http://dx.doi.org/10.1111/j.1547-5069.2011.01419.x

Polit, D. F., \& Beck, C. T. (2006). Essentials of Nursing Research: Methods, Appraisal, and Utilization (6th ed.). Philadelphia, PA: Lippincott Williams \& Wilkins.

Schaufeli, W. B., \& Bakker, A. B. (2004). Job Demands, Job Resources, and Their Relationship with Burnout and Engagement: A Multi-Sample Study. Journal of Organizational Behavior, 25, 293-315. http://dx.doi.org/10.1002/job.248

Schaufeli, W. B., Martínez, I. M., Marques Pinto, A., Salanova, M., \& Bakker, A. B. (2002). Burnout and Engagement in University Students: A Cross-National Study. Journal of Cross-Cultural Psychology, 33, 464-481. http://dx.doi.org/10.1177/0022022102033005003

Seo, Y., Ko, J., \& Price, J. (2004). The Determinants of Job Satisfaction among Hospital Nurses: A Model Estimation in Korea. International Journal of Nursing Studies, 41, 437-446. http://dx.doi.org/10.1016/j.ijnurstu.2003.11.003

Seppälä, P., Mauno, S., Feldt, T., Hakanen, J., Kinnunen, U., Tolvanen, A., \& Schaufeli, W. B. (2009). The Construct Validity of the Utrecht Work Engagement Scale: Multi-Sample and Longitudinal Evidence. Journal of Happiness Studies, 10, 459-481. http://dx.doi.org/10.1007/s10902-008-9100-y

Simpson, M. (2009a). Engagement at Work: A Review of the Literature. International Journal of Nursing Studies, 46, $1012-$ 1024. http://dx.doi.org/10.1016/j.ijnurstu.2008.05.003

Simpson, M. (2009b). Predictors of Work Engagement among Medical-Surgical Registered Nurses. Western Journal of 
Nursing Research, 31, 44-65. http://dx.doi.org/10.1177/0193945908319993

Steptoe, A., Gibson, E. L., Hamer, M., \& Wardle, J. (2007). Neuroendocrine and Cardiovascular Correlates of Positive Affect Measured by Ecological Momentary Assessment and by Questionnaire. Psychoneuroendorinology, 32, 56-64. http://dx.doi.org/10.1016/j.psyneuen.2006.10.001

Thian, J. H. M. (2012). Examining the Interrelationships among Stress, Positive Affectivity, and Work Engagement among Registered Nurses Working in General Ward Settings in Singapore. Unpublished Thesis, Singapore City: Alice Centre for Nursing Studies, Yong Loo Lin School of Medicine, National University of Singapore.

Thian, J. H. M., Kannusamy, P., \& Klainin-Yobas, P. (2013). Stress, Positive Affectivity, and Work Engagement among Nurses: An Integrative Literature Review. Singapore Nursing Journal, 40, 24-33.

Van Yperen, N. W. (2003). On the Link between Different Combinations of Negative Affectivity (NA) and Positive Affectivity and Job Performance. Personality and Individual Differences, 35, 1873-1881. http://dx.doi.org/10.1016/S0191-8869(03)00036-9

Watson, D., Clark, L. A., \& Tellegen, A. (1988). Development and Validation of Brief Measures of Positive and Negative Affect: The PANAS Scales. Journal of Personality and Social Psychology, 54, 1063-1070. http://dx.doi.org/10.1037/0022-3514.54.6.1063

Wu, H., Chi, T. S., Chen, L., Wang, L, \& Jin, Y. P. (2010). Occupational Stress among Hospital Nurses: Cross-Sectional Survey. Journal of Advanced Nursing, 66, 627-634. http://dx.doi.org/10.1111/j.1365-2648.2009.05203.x 
Scientific Research Publishing (SCIRP) is one of the largest Open Access journal publishers. It is currently publishing more than 200 open access, online, peer-reviewed journals covering a wide range of academic disciplines. SCIRP serves the worldwide academic communities and contributes to the progress and application of science with its publication.

Other selected journals from SCIRP are listed as below. Submit your manuscript to us via either submit@scirp.org or Online Submission Portal.
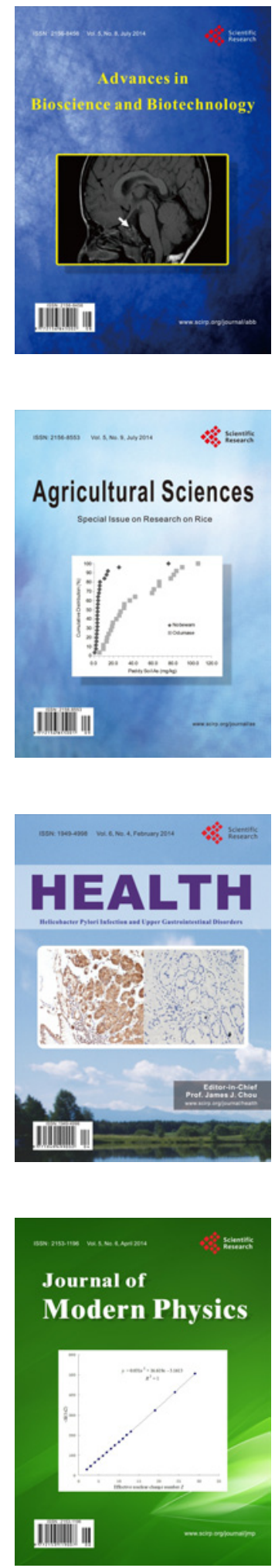
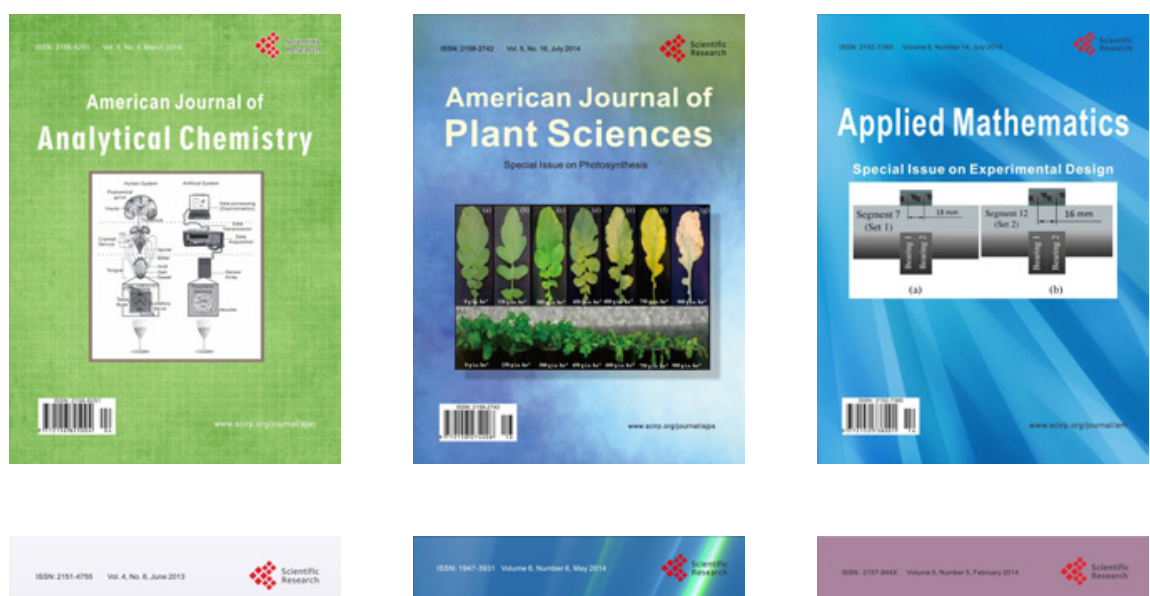

Creative Education
